Revista Universo Contábil, ISSN 1809-3337

FURB, v. 7, n. 2, p. 6-27, abr./jun., 2011

doi:10.4270/ruc. 2011210

Disponível em www.furb.br/universocontabil

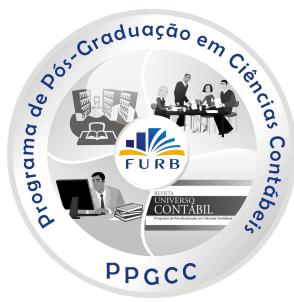

UM ESTUDO SOBRE A ASSOCIAÇÃO ENTRE MODELO DE GESTÃO E CONTROLES GERENCIAIS EM INDÚSTRIAS BRASILEIRAS 1

\title{
AN STUDY ABOUT THE ASSOCIATION BETWEEN THE MANAGEMENT MODEL AND MANAGEMENT CONTROLS OF BRAZILIAN INDUSTRIES
}

\author{
Luciane Reginato \\ Doutora em Controladoria e Contabilidade pela FEA/USP \\ Professora do Departamento de Contabilidade e Atuária da FEA/USP \\ Endereço: Av. Professor Luciano Gualberto, 908 - Prédio FEA 3 \\ CEP: 05508-010 - São Paulo/SP - Brasil \\ E-mail: luciregi@terra.com.br \\ Telefone: (11) 3091-5820 \\ Reinaldo Guerreiro \\ Doutor em Controladoria e Contabilidade pela FEA/USP \\ Professor do Departamento de Contabilidade e Atuária da FEA/USP \\ Endereço: Av. Professor Luciano Gualberto, 908 - Prédio FEA 3 \\ CEP: 05508-010 - São Paulo/SP - Brasil \\ E-mail: reiguerr@usp.br \\ Telefone: (11) 3091-5820
}

\section{RESUMO}

O objetivo deste estudo consistiu em investigar a associação entre os elementos do modelo de gestão e os tipos de controles gerenciais adotados pelas empresas industriais brasileiras. Os elementos do modelo de gestão investigados no presente estudo contemplaram a organização, o planejamento, a execução e o controle, ao passo que os controles gerenciais foram segregados em métodos e sistemas de custeio, indicadores de avaliação de desempenho e filosofias e conceitos aplicados para fins de controle gerencial. Foram contatadas 80 indústrias brasileiras, classificadas pela Revista Exame, que, anualmente, divulga na mídia as Melhores e Maiores empresas do Brasil, obtendo-se um retorno de 45 delas (56,3\%). A coleta de dados desenvolveu-se por meio da aplicação de instrumento de pesquisa respondido por gestores do

1 Artigo recebido em 07.05.2010. Revisado por pares em 17.08.2010. Reformulado em 21.09.2010. Recomendado para publicação em 28.09.2010 por Ilse Maria Beuren (Editora). Publicado em 30.06.2011. Organização responsável pelo periódico: FURB. 
alto escalão que pudessem ter uma visão sistêmica da empresa, cujo período compreendeu os meses de junho a agosto de 2009. Para análise dos dados foram aplicadas técnicas de análise multivariada, que consistiram em estatística descritiva e modelagem de equações estruturais. Os resultados mostraram níveis significativos de associação entre as variáveis dentro de seu constructo, bem como evidenciou relevante associação entre o constructo modelo de gestão e o constructo controles gerenciais, indicando, portanto, que os elementos organização, planejamento, execução e controle do modelo de gestão têm significativa associação com os tipos de controles gerenciais adotados pelas empresas investigadas.

Palavras-chave: Modelo de gestão. Controles gerenciais. Constructos.

\section{ABSTRACT}

The aim of this study was to investigate the association level between the management model elements and the types of management controls adopted by industrial companies in Brazil. The elements of the management model investigated in this study include organizing, planning, execution and control, while management controls were segregated into methods and costing systems, indicators of performance evaluation and philosophies and concepts applied for the purpose of managerial control. It were contacted 80 Brazilian industries, ranked by Exame magazine which annually publishes in the media Best Big Companies in Brazil, resulting in a return of 45 (56.3\%). Data collection was developed through the application of research instrument answered by senior managers who might have a systemic vision of the company, which comprised the period from June to August 2009. For the data analysis techniques were applied to multivariate analysis, which consisted of descriptive statistics and structural equation modeling. The results showed significant levels of association between the variables within your construct and the construct management model showed significant association with the construct management controls, indicating therefore that the information organization, planning, execution and control of the management model have significant association with the types of management controls adopted by the companies investigated.

Keywords: Management model. Management controls. Constructs.

\section{INTRODUÇÃO}

A estabilidade de uma empresa depende do funcionamento sistêmico e harmônico de suas partes, como pressupõe a teoria geral dos sistemas (BERTALANFFY, 1977). Uma das possíveis dificuldades para que a interação adequada entre elas aconteça pode estar relacionada ao envolvimento das pessoas nas atividades da empresa, cujas crenças e valores nem sempre são convergentes. Segundo Kotter e Heskett (1992, p.10), o comportamento das pessoas, que consequientemente forma a cultura da empresa, pode ser um fator influente sobre a gestão dos ambientes externo e interno, talvez seja "maior do que todos os fatores discutidos com maior freqüência na literatura empresarial - estratégia, estrutura organizacional, sistemas administrativos, instrumentos de análise financeira, liderança". Nessa linha, as crenças e os valores, essencialmente dos lideres da empresa, podem ser indutores de ações que levem as pessoas a convergirem ou não para um mesmo fim.

As razões para que uma empresa apresente desempenho distinto de outra, mesmo pertencendo ao mesmo setor de atividade e usufruindo de recursos iguais ou semelhantes, podem estar nas distinções entre os padrões de seus modelos administrativos, na forma como são geridos os recursos humanos e suas potencialidades, em síntese, no ambiente interno. 
O modelo de gestão, composto por características pessoais, valores e crenças dos líderes da empresa, pode ser um fator estimulante para o funcionamento e a interação entre as áreas e as pessoas na empresa. Pode ser este modelo o delineador da capacidade gerencial da empresa, podendo ou não impulsionar as habilidades e competências de seus gestores e influenciar o exercício de suas atividades, encorajando-os em maior ou menor grau a agirem de forma congruente com as necessidades que o dinamismo ambiental requerer (GUERREIRO, 1989).

O modelo de gestão, sob a ótica de autores clássicos, tais como Likert (1975), Robbins (1978), Taylor (1995) e Catelli (2001), pode ser contemplado por meio de elementos tais como: estrutura organizacional, definição de funções, níveis de descentralização e centralização, estilo, planejamento, execução, controle, entre outros, que também se constituem em importantes orientadores da postura dos gestores, podendo, por esse motivo, potencializar a capacidade de reação da empresa às turbulências ambientais. Ressalte-se que a variação e a intensidade desses elementos pode se modificar de uma para outra empresa, o que depende de inúmeros fatores inerentes a cada uma delas.

Não raras vezes, têm-se notícias de empresas que atuam em um mesmo segmento, disputando o mesmo mercado, usufruindo da mesma tecnologia e outros aspectos similares, mas que, contudo, apresentam resultados completamente diferentes. As razões para isto podem estar nas distinções de suas capacidades gerenciais, que, conforme Guerreiro (1989), são oriundas, fundamentalmente, das crenças, valores e convicções dos empreendedores e dos administradores da empresa, isto é, de seu modelo de gestão.

Há de se considerar, ainda, que as práticas ou controles gerenciais adotados por uma empresa para nortear o seu processo decisório e o de avaliação de desempenho podem ser influenciados por seu modelo de gestão, partindo do conceito dado pelos autores, como Guerreiro (1989) e Catelli (2001). Assim, instrumentos de gestão consagrados, por exemplo, o planejamento empresarial e os sistemas e métodos de avaliação e mensuração, podem ter os seus formatos significativamente diferentes entre uma e outra empresa, variando de acordo com as suas próprias características e, principalmente, com os setores de mercado em que atuam, conforme apontou a pesquisa realizada por Reginato (2010).

Nesse âmbito, os elementos do modelo de gestão podem interferir na escolha dos tipos de controles gerenciais usados para apoiar a gestão empresarial (ANDERSON et al., 1989). Os controles gerenciais englobam vários instrumentos focados na mensuração de atividades ou processos, no processamento de dados e disponibilização de informações aos gestores, na facilitação da entrada e processamento de recursos e saída de bens e serviços (ANDERSON et al., 1989; LOUDERBACK III et al., 2000; CHENHALL, 2003). Cabe a cada empresa a escolha daqueles compatíveis com suas necessidades e com seus objetivos.

Nesse ínterim, a questão norteadora desse estudo culminou em responder: Quais as associações existentes entre os elementos do modelo de gestão e os tipos de controles gerenciais adotados por empresas industriais brasileiras? A fim de responder a referida questão, o objetivo do estudo foi o de investigar as associações entre os elementos do modelo de gestão - organização, planejamento, execução e controle e os controles gerenciais métodos e sistemas de custeio, indicadores de avaliação de desempenho e as filosofias e os conceitos aplicados para fins de controle gerencial. Cada elemento e cada controle são devidamente esmiuçados ao longo do presente trabalho.

\section{REFERENCIAL TEÓRICO}

\subsection{Modelo de gestão: uma construção a partir das funções da gestão}

Os modelos empresariais de gestão foram, primeiramente, amparados e sistematizados em meio às bases filosóficas de cientistas e filósofos, como René Descartes, Isaac Newton e 
Francis Bacon, cujos pensamentos tiveram importância marcante na cultura da qual emergiram as teorias administrativas, influenciando, consideravelmente, a construção da sociedade industrial (NASCIMENTO; REGINATO, 2010).

A visão mecanicista, representada pelos teóricos e propositores Taylor, Ford e Fayol, também marcou a sociedade industrial, tocando em pontos como: a) produtividade e eficiência na produção, princípios do planejamento, preparação, controle e execução do trabalho (TAYLOR, 1995); b) invenção de Ford da linha de montagem na produção, ressaltando os princípios de intensificação, economicidade, produtividade (MAXIMIANO, 1995); c) divisão de trabalho, autoridade e responsabilidade, disciplina, unidade de comando, unidade de direção, subordinação, remuneração do pessoal, centralização, hierarquia, ordem, equidade, estabilidade do pessoal, trabalho em equipe e iniciativa das pessoas (FAYOL, 1989). A partir disso, as funções ou elementos da gestão parecem ter se consolidado.

Diversos são os autores que tratam dos elementos de uma gestão. Por meio da revisão de literatura percebe-se que as tarefas de uma administração, como as de planejar, executar, controlar, organizar, coordenar, têm sido estudadas por autores consagrados no âmbito da administração, coforme mencionado anteriormente. Entre eles encontra-se Fayol (1989), que já sumarizava os elementos essenciais de uma gestão como sendo a previsão, a organização, o comando, a coordenação e o controle.

Também Stoner e Freeman (1985), Fayol (1989) e Daft (2004) desenvolveram a ideia de que uma administração deve se ater ao planejamento, à organização, à liderança e ao controle. Robbins (1978) fez alusão aos mesmos elementos expostos, classificando-os em planejamento, organização, liderança e avaliação. Com essa mesma abordagem, Steiner e Miner (1981) trataram os elementos da gestão. Para eles, o planejamento deve incluir todas as decisões que cercam as atividades da empresa, o controle dos planos deve ter incutido em seu processo a avaliação do desempenho organizacional, e as atividades e relações entre as pessoas precisam ser coordenadas.

O que fica transparente, ao compilar os elementos de gestão entre a diversidade de bibliografias existentes, essencialmente as que tangem às ciências administrativas, é que a empresa pode ser visualizada por meio de tarefas fundamentais de gestão, tais como, prever organizar, comandar, coordenar e controlar, como já era estudado por Fayol. Tais tarefas foram expandidas e reclassificadas por outros autores, inserindo-se grupos que espelham os aspectos de relacionamento humano e informacionais, por exemplo. Esses elementos, oriundos das teorias da administração, oferecem o suporte para o entendimento de modelo de gestão, sob a ótica desse estudo.

No Brasil, o assunto Modelo de Gestão foi inicialmente discutido, conceituado e entendido pelos estudiosos Armando Catelli e Reinaldo Guerreiro, junto com seu grupo de estudos sobre Gestão Econômica. Eles apresentaram os princípios e as diretrizes de um modelo de gestão. O modelo de gestão, segundo Guerreiro (1989), é caracterizado por um conjunto de princípios que devem ser observados, que expressam as crenças, valores e aspirações dos proprietários, sucessores e lideres da empresa. Segundo o autor, esses princípios existem para que se observe e procure garantir que:

a) a missão da empresa seja cumprida;

b) seja inserida na empresa uma estrutura adequada que ofereça o devido suporte às suas atividades e ao seu funcionamento sistêmico;

c) se institucionalize um estilo de gestão condutor para a criação de uma cultura que permita a integração das pessoas em torno dos objetivos estabelecidos pela empresa;

d) a execução dos planos preestabelecidos, conjuntamente com os recursos utilizados para tal execução, sejam devidamente aferidos, a fim de que os possíveis desvios provenientes de desajustes na operacionalização dos planos sejam corrigidos; 
e) as variáveis do ambiente externo, bem como as do ambiente interno, sejam observadas atentamente para que, em caso de necessidade, novos recursos sejam disponibilizados no processamento dos bens e serviços propostos pela empresa.

O modelo de gestão pode ser visto como sendo o conjunto de princípios, nem sempre formalizados, contemplado por meio da observância dos instrumentos de gestão, tais como planejamento, controle, sistemas de informações, e demais práticas gerenciais adotadas na empresa. Em outras palavras, ele constitui um conjunto de crenças e valores a respeito da maneira como administrar uma empresa. Dele decorre uma série de diretrizes que impactam os subsistemas e o sistema organizacional. Essas diretrizes mostram se a empresa tem ou não planejamento e controle, qual o grau de participação dos gestores nas decisões, quais os critérios de avaliação de desempenho, quais os papéis dos gestores na empresa, entre outros. (GUERREIRO, 1989; CATELLI, 2001).

Catelli (2001) propôs alguns princípios alicerçados na visão sistêmica da empresa, que servem de base para o modelo de gestão. São eles:

a) processo decisório descentralizado;

b) funções e responsabilidades definidas claramente e decorrentes da missão;

c) autoridade compatível com as funções e responsabilidades;

d) estilo participativo;

e) postura empreendedora por parte dos gestores;

f) processo de gestão - planejamento estratégico, planejamento operacional, execução e controle;

g) avaliação de desempenho baseada no resultado econômico da empresa.

Salienta-se que esses princípios, divulgados pelos autores, são oriundos do comportamento ou da cultura das pessoas na empresa (fruto dos já mencionados valores, crenças e aspirações). Nessa linha, estudos mostraram que os referidos valores e as crenças influenciam a estrutura da empresa (DEAL; KENNEDY, 1982), bem como impactam, além da estrutura e modelo de gestão, os seus desempenhos operacionais e econômicos (GORDON; DITOMASO, 1992; MARCOULIDES; HECK, 1993), e os tipos de instrumentos gerenciais adotados pelas empresas (REGINATO, 2010).

Para fins deste trabalho, estudou-se o modelo de gestão segregado em elementos, cujo constructo teve como base primária as funções da gestão, apregoadas pelos autores das teorias administrativas. Os quatro elementos tratados envolvem: a organização, o planejamento, a execução e o controle. A organização engloba as funções e responsabilidades, o poder e a autoridade, a estrutura organizacional e o estilo de gestão, aspectos esses que se destinam a formatar o desenho da empresa. Os demais elementos refletem o processo de gestão da empresa. Veja-se a Figura 1, a fim de se visualizar este primeiro constructo.

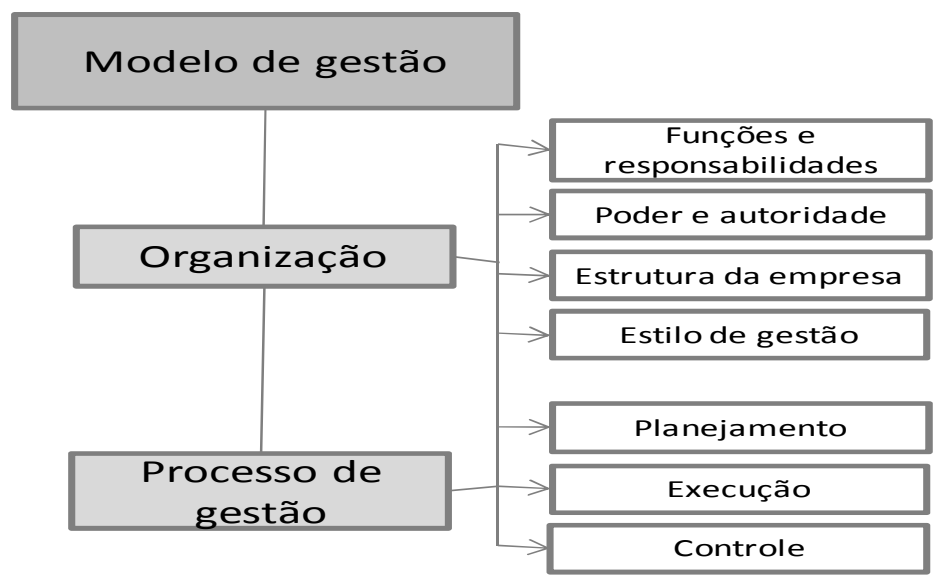

Figura 1 - Constructo do Modelo de gestão 
A seguir apresenta-se o segundo constructo estudado neste trabalho: controles gerenciais.

\subsection{Controles gerenciais}

Encontra-se, em diversas obras da literatura nacional e estrangeira, o termo contabilidade gerencial para expressar o conteúdo de controle gerencial. A contabilidade gerencial pode ser entendida como "o processo de identificação, mensuração, acumulação, análise, preparação, interpretação, e comunicação de informações financeiras usadas pela administração para planejar, avaliar, e controlar dentro de uma empresa e assegurar o uso apropriado e responsável de seus recursos" (ATKINSON et al., 2000, p. 67).

Para Anderson et al. (1989, p. 1), as práticas e os procedimentos da contabilidade gerencial são usados para auxiliar as ações da gestão interna. Chenhall (2003) se reporta à contabilidade gerencial como sendo um conjunto de práticas, que englobam, por exemplo, orçamento empresarial e custeio de produtos. Anderson et al. (1989) e Louderback III et al. (2000) inseriram, nesse conjunto, os instrumentos de planejamento e controle, a fim de se proverem informações para os gestores, orientando-os sobre o seu uso nas tomadas de decisões e, conseqüientemente, no curso de suas ações.

Assim, pode-se depreender que a contabilidade gerencial abarca as práticas gerenciais utilizadas para gerar informações aos gestores de todos os níveis hierárquicos, a fim de tomarem decisões e controlarem os resultados, sejam elas envoltas por sistemas de custeio, sistemas de avaliação de desempenho ou outras práticas que a empresa venha a adotar. Saliente-se que não há um sistema de controle ou contabilidade gerencial que possa ser aplicado, igualmente, a todas as organizações e em todas as circunstâncias, isso dependerá da necessidade de cada organização para um determinado momento (OTLEY, 1980).

Como exposto pelos autores Chenhall (2003), Anderson et al. (1989) e Louderback III et al. (2000), a contabilidade gerencial, aqui vista como controle gerencial, consiste em um conjunto de práticas, que engloba vários instrumentos voltados a mensurar atividades ou processos, processar dados e disponibilizar informações úteis para a tomada de decisões dos gestores. A Figura 2 revela a estrutura tratada neste constructo.

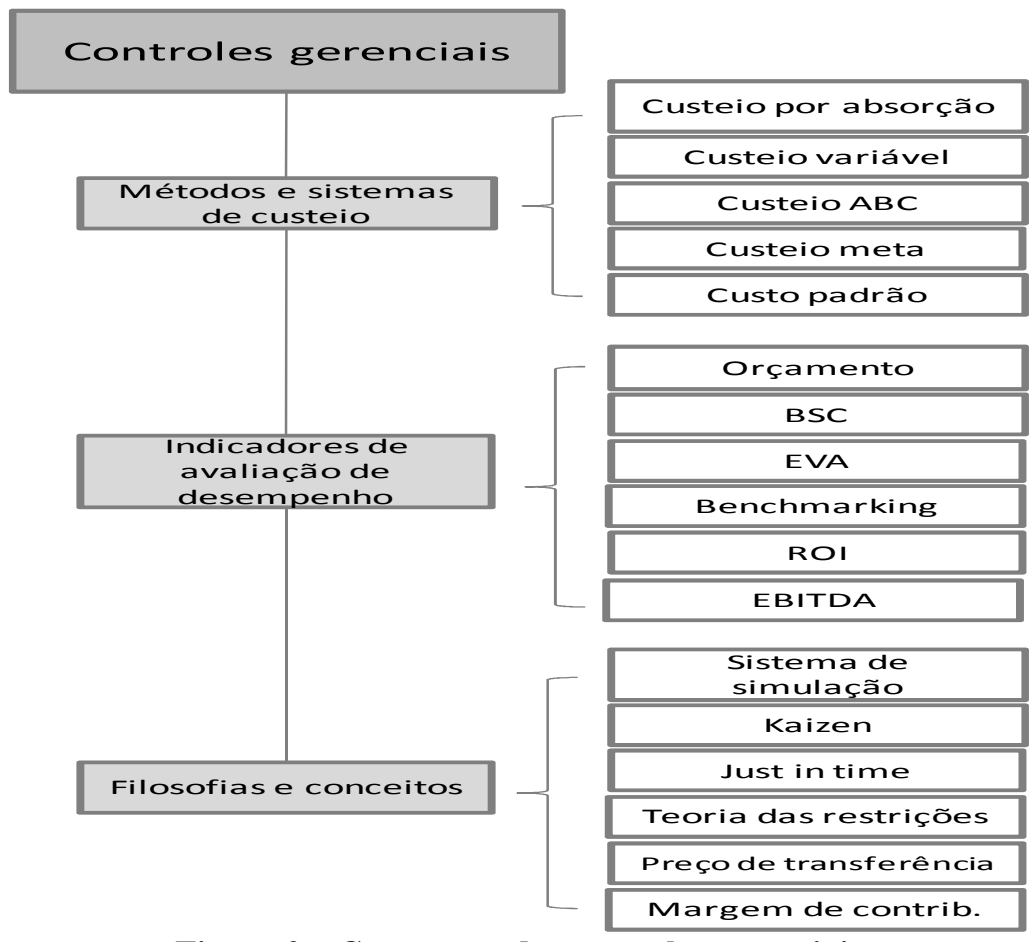

Figura 2 - Constructo dos controles gerenciais 
A seguir os controles são comentados individualmente.

\subsubsection{Métodos e sistemas de custeio}

No que tange ao objetivo do controle gerencial, na forma de métodos e sistemas de custeio, Martins (2003) evidenciou que é fornecer dados para o estabelecimento de padrões, orçamentos e outras formas de previsão e, em uma etapa posterior, acompanhar o que de fato aconteceu a fim de comparar isso com os valores previamente estabelecidos.

Para Martins (2003) existem os custeios por absorção, o custeio variável, o ActivityBased Costing $(A B C)$ ou custeio baseado em atividades. Já Padoveze (2004) tratou, como método, o custeio variável, por absorção, integral e o $A B C$ e como sistemas de custeio o custo real, o estimado/orçado e o custo-padrão.

Coad (1999), por seu turno, considerou $A B C, A B M$, contabilidade de ganhos, gestão da cadeia de valor, balanced scorecard, custeio meta, gestão de custo Kaizen, entre outros, como um conjunto de abordagens abrangidas pela contabilidade ou controle gerencial. Nessa linha, Hughes e Gjerde (2003) desenvolveram uma pesquisa nas empresas americanas e puderam constatar que os sistemas de custeio utilizados por elas envolvem: $A B C$, sistemas tradicionais, custeio variável e teoria das restrições, sendo que os sistemas tradicionais, como absorção, são os mais freqüentemente empregados.

Sulaiman et al. (2004) desenvolveram estudo em empresas asiáticas para examinar o grau de utilização dos métodos de custeio, separando-os em tradicionais e contemporâneos. As evidências do estudo indicaram que os tradicionais foram compostos pelo custeio padrão, custo-volume-lucro, ROI, orçamentos, e os contemporâneos cercaram-se do ABC, TQM, Custeio meta e Balanced Scorecard.

Claro está que a literatura trata dos métodos e sistemas de custeio de forma abrangente, muitas vezes não diferenciando um e outro grupo. Entretanto, Soutes e Guerreiro (2007) compilaram tais grupos, apresentando-os em um trabalho sobre os métodos e sistemas de custeio modernos e contemporâneos e agruparam-nos sugerindo o custeio por absorção, o custeio variável, o custeio baseado em atividades, o custeio padrão e o custeio meta como métodos e sistemas de custeio; o preço de transferência, a moeda constante, o valor presente, o benchmarking e o EVA como sendo métodos de avaliação e medidas de desempenho; enquanto o orçamento, as simulações, o Kaizen, Just in Iime, teoria das restrições e Balanced Scorecard foram classificados no grupo de filosofias e modelos de gestão.

Para fins deste estudo são tratados como métodos e sistemas de custeio o custeio por absorção, o custeio variável, o custeio $\mathrm{ABC}$, o custo padrão e o custeio meta. $\mathrm{O}$ custeio por absorção é aquele em que todos os custos de fabricação, variáveis e fixos, são inventariáveis (HORNGREN et al., 2000). Quanto ao custeio variável, o primeiro artigo relevante que divulgou, de forma sistemática, esse custeio e suas vantagens foi o de Jonatham N. Harris intitulado What Did We Earn Last Month?, publicado em 1936. Nesse método, todos os custos de produção e despesas são separados em fixos e variáveis, e só os variáveis são considerados para cômputo final dos custos e despesas (SANTOS; NININ, 1999).

$\mathrm{O}$ terceiro custeio tratado aqui diz respeito ao custeio baseado em atividades $(A B C)$. Ele baseia-se na premissa de que são as atividades e não os produtos que provocam o consumo de recursos e, portanto, formam os custos dos produtos (KAPLAN; COOPER, 1998). Já, o custo padrão consiste em um instrumento de controle dos custos de produção. Conhecendo-se o bem produzido pela empresa, pode-se orçar o quanto seria o custo padrão dele, se não ocorressem desvios ou falhas na produção (SAKURAI, 1997).

Como último custeio estudado, tem-se o custeio meta, que consiste no processo de planejamento de resultados, no qual os preços de venda estabelecidos pelo mercado e as margens estabelecidas pela empresa ganham realce (HANSEN, 2002).

Na seqüência é apresentado o segundo grupo de controles gerenciais. 


\subsubsection{Indicadores de avaliação de desempenho}

Como indicadores de avaliação de desempenho são contemplados o Orçamento, o Balanced Scorecard, o EVA, Benchamarking, ROI, e EBITDA.

O orçamento, segundo Anthony e Govindarajan (2002, p. 461), consiste em "um instrumento importante para o planejamento e o controle das empresas a curto prazo. Geralmente, um orçamento operacional cobre um ano e inclui as receitas e as despesas previstas". De acordo com Nascimento e Reginato (2010), o orçamento é a parcela mais detalhada do plano de negócios da empresa, quando são reavaliadas a missão e a visão da empresa e estabelecidos os seus objetivos. As características que envolvem esse processo são decorrentes do modelo de gestão da empresa.

Em se tratando do Balanced Scorecard ( BSC), pode ser entendido como um sistema de suporte à decisão, visto que reúne os elementos-chave para o acompanhamento do cumprimento da estratégia, podendo ser um sistema de controle da empresa (KAPLAN; NORTON, 1997). Já, a medida Economic Value Added (EVA) é compreendida como coadjuvante no sistema de planejamento e controle da empresa, permitindo que os gestores avaliem o valor adicionado da empresa (STEWART, 1990).

O Benchmarking consiste no processo de comparação dos produtos, serviços e práticas empresariais entre os mais fortes concorrentes ou empresas reconhecidas como líderes no segmento em que a empresa analista está atuando (TEN HAVE, 2003; VOSS et al., 1997).

Os indicadores Return on Investment (ROI) e Earning Before Interest, Taxes, Depreciation and Amortization (EBITDA) também, como o EVA, podem ser utilizados como auxiliares no processo de gestão da empresa. O primeiro diz respeito ao lucro antes do imposto de renda e antes de despesas financeiras dividido pelo ativo total da empresa. Isso define o desempenho global da empresa, ou seja, quanto os seus proprietários conseguiram obter sobre os investimentos realizados, após descontados os custos e as despesas operacionais (MARTINS, 2003), ao passo que o segundo é uma forma de medir desempenho da empresa em termos de fluxo de caixa e de auxiliar no processo de avaliação da empresa como um todo, observando, basicamente, a capacidade de geração de recursos dos ativos (MARTINS, 2003).

\subsubsection{Filosofias e conceitos aplicados para fins de controle gerencial}

Tendo em vista as classificações de autores tais como Soutes e Guerreiro (2007), no grupo filosofias e conceitos aplicados para fins gerenciais encontram-se os sistemas de simulação, Kaizen, Just in Time, teoria das restrições, preço de transferência e margem de contribuição. Isso se dá devido à falta de clareza nas distinções entre métodos, sistemas, indicadores e demais controles. Segundo esses autores, tem-se um conjunto de conceitos e de filosofias que não são tratados com clareza pela literatura, porém merece destaque.

Os sistemas de simulação consistem em uma técnica que possibilita, por intermédio de experimentos, estudar o comportamento de um sistema ou de um modelo que o represente de forma simplificada. Dentre alguns modelos da pesquisa operacional, podem-se citar: teoria das filas, diagramas de árvores de decisão, teoria dos jogos, redes neurais, programação linear, programação não linear e goal programming (PIDD, 1998; TURBAN et al., 2004; MOORE; WEATHERFORD, 2005).

Visando à suportar o processo de redução de custos dentro do contexto do atual sistema produtivo e dos atuais produtos fabricados na empresa, se tem o Kaizen, como filosofia para fins de controle gerencial (MONDEN, 1993). Também como filosofia aparece o Just in Time, que é uma filosofia japonesa de organização da produção, na qual os estoques são vistos como causa da possível ineficiência existente no processo produtivo. Para os seguidores dessa filosofia, os estoques não existem, mas se existirem devem ser eliminados 
com vistas à reduzir ao máximo os custos de produção (TEN HAVE, 2003).

$\mathrm{Na}$ linha de conceitos, surgem a teoria das restrições, o preço de transferência e a margem de contribuição. A primeira baseia-se no princípio de que existe uma causa comum para muitos efeitos e que isso leva a uma visão sistêmica da empresa, ou seja, a empresa é um conjunto de elementos entre os quais há alguma relação de interdependência. Segundo Guerreiro (1995), a teoria das restrições apresenta um enfoque diferenciado, considerando os princípios da otimização da produção, os procedimentos de sincronização da produção e as proposições relativas ao gerenciamento das restrições.

O preço de transferência é apresentado como um conjunto de regras que uma empresa usa para distribuir a receita entre os centros de responsabilidade (ATKINSON et al., 2000). O último conceito, margem de contribuição, é tido como resultado da diferença entre receita e custos e despesas variáveis associados a um ou diversos produtos. $\mathrm{O}$ seu conceito direciona-se para a análise da rentabilidade da empresa (HORNGREN et al., 2000).

\subsubsection{Associação entre modelos de gestão e controles gerenciais: estudos precedentes}

Não se observou a existência de pesquisas que tiveram como objetivo central relacionar os elementos do modelo de gestão e os controles gerenciais, na forma como abordado pelo presente estudo. Diversos estudos são encontrados, porém com vertentes teóricas diferentes. Alguns relacionam as variáveis do ambiente externo com controles gerenciais específicos, como na abordagem contingente; outros relacionam os referidos controles com desempenhos das empresas, usando a cultura organizacional como suporte teórico.

Para a realização desta pesquisa, alguns estudos precedentes serviram de inspiração, tais como o de Guerreiro (1989) ao tratar de modelo de gestão em sua tese de doutorado; Soutes e Guerreiro (2007), que verificaram se as empresas utilizam os controles gerenciais, analisando se aquelas que os possuem apresentam desempenhos diferentes daquelas que não os possuem; bem como o estudo mais recente realizado por Reginato (2010), que evidenciou a utilização de cada controle gerencial por empresas de setores de mercado distintos, e suas relações com as variáveis dos ambientes externo e interno e com o desempenho.

Dado, sucintamente, o amparo teórico deste estudo, procedeu-se aos passos metodológicos que viabilizaram esse estudo.

\section{METODOLOGIA}

\subsection{População e amostra}

A população deste estudo cercou-se das 1000 (mil) maiores empresas, classificadas pela Revista Exame, que, anualmente, divulga na mídia as Melhores e Maiores empresas do Brasil. Dessas empresas, optou-se por trabalhar com um setor de mercado: o industrial.

A amostragem foi não aleatória, caracterizando-se por ser intencional. Nesse sentido, dentro do mesmo setor, foram contatadas 80 empresas, obtendo-se um retorno de 45 delas $(56,3 \%)$. Em relação ao tamanho da amostra, procurou-se respeitar o número de variáveis latentes investigadas e a viabilidade dos retornos das empresas. Hair et al. (2007) defendem que o número de empresas deve corresponder a, no mínimo, cinco vezes o número de variáveis latentes investigadas. Assim, calculou-se que o número de respostas obtidas neste trabalho respeitou o pressuposto.

\subsection{Coleta dos dados}

A coleta de dados para a pesquisa desenvolveu-se por meio da aplicação de 
instrumento de pesquisa respondido por gestores do alto escalão que pudessem ter uma visão sistêmica da empresa (presidência, diretoria e, em alguns casos, a controladoria por indicação do diretor responsável). $\mathrm{O}$ instrumento foi disponibilizado em meio virtual para facilitar o seu acesso pelos respondentes, cuja construção em ambiente de Internet utilizou como amparo a tecnologia de Business Intelligence (BI) (tabelas dinâmicas). Quanto à escala, usada no instrumento de pesquisa, adotou-se uma valoração de zero a dez. Essa escala foi utilizada para facilitar a compreensão por parte dos respondentes da pesquisa e para respeitar o uso posterior da modelagem de equações estruturais, conforme preconizado pela literatura que trata desse assunto (HAIR et al., 2007; HENSELER et al., 2009).

Depois de concluídas as etapas de definição da amostra, construção e disponibilização do instrumento de pesquisa, organizou-se um protocolo para o estudo contendo os procedimentos que foram adotados para a pesquisa de campo: a) carta de apresentação; b) organização dos relatórios - nome das empresas, localização, telefone; estratégia de envio da correspondência - após contato telefônico, o link com os questionários foram enviados via $e$ mail, juntamente com a carta de apresentação; c) período de realização da pesquisa - entre junho e agosto de 2009.

\subsection{Análise dos dados}

A hipótese estabelecida para o estudo foi a de que os elementos do modelo de gestão têm nível significativo de associação com os tipos de controle gerencial adotados pelas empresas.

Para atender ao objetivo e aceitar ou rejeitar a hipótese, aplicaram-se técnicas de análise multivariada, que consistiram em estatística descritiva e modelagem de equações estruturais. Os softwares de análise de dados empregados foram o Statistical Package for the Social Sciences (SPSS), versão 16, e o pacote Partial Least Squares (SmartPLS 2).

Quanto à estatística descritiva, primeiramente estruturou-se a distribuição de frequiência relativa devidamente transformada em percentual, para fins de melhor visualização das porções contrapostas às observações totais.

Em relação ao uso da modelagem de equações estruturais, ela foi utilizada para estimar relações de dependência simultâneas, explicando o erro de mensuração no processo de estimação. Foram desenhados constructos teóricos para posterior aplicação. Pôde-se, por meio dessa técnica, relacionar os dois constructos (modelo de gestão e controles gerenciais) e suas variáveis dentro de cada constructo ao mesmo tempo, ou seja, esta técnica permite que essas relações sejam simultaneamente analisadas, individual e conjuntamente.

As análises se basearam nas avaliações dos modelos de mensuração e estrutural (HAIR et al., 2007; HENSELER; RINGLE; SINKOVICS, 2009), os quais englobaram os pressupostos a seguir:

a) AVE (Average Variance Extracted) - a variância média extraída superior a 0,5;

b) Confiabilidade composta - medida não inferior a 0,7 (HENSELER et al., 2009).

c) $\mathrm{R}^{2}$ - quanto maior for o $\mathrm{R}^{2}$, tanto maior será o poder explicativo do modelo (HENSELER et al., 2009; COOPER; SCHINDLER, 2004);

d) Alfa de Cronbach - avalia a consistência interna de um constructo sendo 0,7 um número que pode servir de parâmetro mínimo aceitável (COZBY, 2003);

e) Validade discriminante - considera-se que há validade discriminante quando as correlações entre as variáveis latentes são menores que a raiz quadrada da AVE, ou então, quando a carga fatorial de cada indicador é maior em sua variável latente do que em outras (CHIN, 1998; MENDES-DA-SILVA et al., 2008).

Saliente-se que, além desses pressupostos, antes de verificar-se a AVE, foram analisadas todas as cargas fatoriais que compuseram os modelos a fim de confirmar se nenhuma delas poderia resultar em baixa confiabilidade e validade. Como valor parâmetro 
para as cargas considerou-se 0,7 . A seguir procedem-se às análises dos resultados.

\section{RESULTADOS}

Essa seção evidencia os resultados obtidos por meio da estatística descritiva e aqueles oriundos da aplicação da modelagem de equações estruturais, oferecendo uma análise conjunta das duas técnicas.

\subsection{Modelo de gestão (MG)}

\subsubsection{Estatística descritiva dos elementos do modelo de gestão}

Resultados obtidos por meio da estatística descritiva no que concerne aos elementos do modelo de gestão.

a) Organização

Para fins de análise dos dados obtidos dos respondentes, organizaram-se as variáveis desse elemento de acordo com as suas semelhanças no que tange aos objetivos de cada questão. As variáveis consistiram em: MG 1 (as funções dos gestores - chefes, supervisores, gerentes e diretores - são claramente definidas), MG2 (a autoridade é delegada a cada gestor de forma que ele execute suas funções sem depender de aprovações de seus superiores), MG 3 (a autoridade e a responsabilidade atribuídas aos gestores são compatíveis com suas funções previamente estabelecidas), MG 4 (as atividades de cada área da empresa são claramente delimitadas, de forma que não existam áreas cinzentas), MG 5 (o poder exercido pelas pessoas na empresa é predominantemente formal), MG 6 (o manual de procedimentos da empresa é sempre atualizado), MG 7 (o organograma da empresa é amplamente divulgado a todos os colaboradores).

Com base na faixa de notas concedidas pelos respondentes, percebeu-se que $51 \%$ das empresas definem claramente as funções entre os gestores de uma e outra área. Considerando que as notas situadas entre 9 e 10 representem a situação ideal de delegação de autoridade para os gestores executarem suas funções sem depender de aprovações de seus superiores, verificaram-se, nessa situação, $36 \%$ das empresas. Também nessa faixa, em $33 \%$ das empresas os níveis de autoridade e responsabilidade não são completamente norteadores das funções dos gestores.

Nessas empresas, em $38 \%$ das vezes as atividades de cada área são claramente delimitadas, de forma que não existam áreas cinzentas, enquanto que apenas $28 \%$ responderam que possuem uma estrutura respaldada pelo poder formal, em que as informações são veiculadas de acordo com o que a administração determina e espera de seus gestores e demais funcionários. Verificou-se que $54 \%$ das empresas sempre atualizam os seus manuais de procedimentos, enquanto que o organograma é divulgado a todos os colaboradores em $46 \%$ dos casos.

As variáveis pesquisadas mostraram significância dentro do elemento organização, revelando valores relativamente altos, entre 0,489 e 0,870. A relação de variável e elemento mais importante foi entre MG4 e organização, mostrando que quanto mais compatibilidade existir entre autoridade e responsabilidade dos gestores e respectivas funções, mais organizadas se demonstram as indústrias investigadas. Por outro lado, o menor peso dentro do elemento organização se destinou ao fato de nem todas as funções dos gestores serem claramente definidas.

b) Planejamento

As variáveis do planejamento se referem a: MG8 (o processo envolvendo a elaboração 
do planejamento estratégico da empresa é formal e possui etapas e cronograma claramente estabelecidos); MG9 (todos os gestores são envolvidos em todas as fases da elaboração do planejamento estratégico); MG10 (as principais estratégias da empresa são divulgadas para todos os seus gestores) e MG11 (o orçamento é elaborado de forma participativa, envolvendo tanto os gestores da alta direção quanto os gestores).

Os resultados apontaram que $46 \%$ das indústrias pesquisadas formalizam os seus processos de planejamento, sendo que em $23 \%$ todos os gestores participam do seu processo. Das respostas, $49 \%$ das empresas registraram que as principais estratégias da empresa são divulgadas para todos os seus gestores, mostrando de certa forma um nível de descentralização.

O orçamento é elaborado de forma participativa em $54 \%$ das empresas do setor industrial. Percebe-se, de modo geral, que em parcela significativa das empresas, os gestores participam ativamente da elaboração do orçamento, denotando que, nessa porção de empresas, se adota um estilo de administração participativo, no que tange à variável analisada.

Notou-se que as cargas das variáveis ficaram entre 0,710 e 0,929 , denotando maior significância para o envolvimento dos gestores em todas as fases da elaboração do planejamento (MG9), enquanto que a relação menos significativa entre variável e elemento se deu em se tratando do envolvimento no planejamento estratégico por meio de etapas e cronograma formais e claramente estabelecidos (MG8).

\section{c) Execução}

A seguir, se evidenciam as cinco variáveis que compõem o elemento execução do modelo de gestão: MG12 (a execução das ações dos gestores é pautada no orçamento); MG13 (os gestores têm plena autonomia para tomarem as decisões necessárias à execução do orçamento de suas áreas); MG14 (as decisões que afetam a empresa como um todo são tomadas após prévia consulta a todos os seus gestores); MG15 (quando da execução do orçamento os gestores sempre privilegiam os objetivos centrais da empresa, mesmo que isso implique prejuízos para as suas próprias áreas) e MG16 (os resultados previstos no orçamento são parâmetro para a avaliação dos desempenhos dos gestores da empresa).

Das empresas em análise, $44 \%$ têm os seus gestores fortemente comprometidos com a execução orçamentária, ou seja, suas ações são pautadas no orçamento. Em $36 \%$ dos casos os respondentes revelaram que os gestores possuem a devida autonomia para executarem as metas estipuladas para suas áreas constantes do orçamento sem ter que solicitar prévia autorização de superiores. Apenas $23 \%$ das respostas indicaram que os gestores são consultados antes de a empresa tomar decisões, o que parece mostrar um nível de centralização em se tratando de decisões que afetam a empresa como um todo.

Tendência semelhante à variável anterior (MG14) é notada quando analisada a MG15, mostrando que somente em $23 \%$ dos casos os gestores privilegiam os objetivos centrais da empresa, no restante das vezes eles parecem priorizar os objetivos de suas próprias áreas. Já, em parte considerável das respostas, $49 \%$, percebe-se que o orçamento é parâmetro na avaliação de desempenho dos gestores da empresa. Essa variável mostra consistência com a MG12 que expressa o orçamento como base para os gestores executarem suas atividades.

As relações entre as variáveis e o elemento execução se mostraram todas significantes, porém com cargas mais baixas do que nos demais elementos, variando entre 0,502 e 0,873. Percebeu-se que a variável mais saliente foi aquela relativa à autonomia que os gestores têm para tomarem decisões necessárias à execução do orçamento, o que mostra consistência com o resultado da variável MG4. Em contrapartida, a relação menos expressiva foi entre o elemento execução e o orçamento como parâmetro para avaliação de desempenho dos gestores da empresa. 


\section{d) Controle}

As três variáveis que compõem o elemento Controle do modelo de gestão se classificam em: MG17 (existe forte comprometimento dos gestores em monitorar e controlar os resultados alcançados em relação àqueles que foram planejados); MG18 (os gestores devem justificar aos seus superiores os desvios observados entre os resultados planejados e os alcançados); MG19 (a empresa realiza reuniões específicas com a participação dos gestores para avaliação dos resultados obtidos).

$\mathrm{Na}$ faixa de notas que pode ser considerada ideal, entre 9 e 10, 62\% das empresas apontaram que os gestores são fortemente comprometidos com o monitoramento e controle dos resultados em relação àquilo que foi planejado. Os modelos de gestão das indústrias, a julgar pelos dados apresentados, evidenciam a importância da fase de controle para suas atividades.

Da mesma forma ocorre com a MG18, que demonstra a concentração de $62 \%$ das respostas. Nesses casos os gestores justificam aos seus superiores os desvios observados entre o planejamento e os resultados alcançados. Com uma concentração ainda maior, de $72 \%$, a MG19 revela que há reuniões na empresa onde os gestores participam para avaliar desempenhos.

Observa-se, em linhas gerais, que a fase de controle é demasiado relevante. Talvez devido à complexidade de operações existente em uma indústria. Todas as variáveis mostraram alto nível de associação com o elemento controle, tanto a MG17, com 0,903; a MG18, com 0,893; e a MG19, com 0,831. Em outras palavras, o comprometimento dos gestores com o monitoramento, a observância dos desvios entre planejamento e resultados alcançados, e a participação dos gestores na avaliação desses resultados mostraram forte relação dentro do elemento controle.

\subsubsection{Avaliação do modelo de mensuração do modelo de gestão}

O modelo de gestão se constitui na variável de $2^{\mathrm{a}}$ ordem e os seus elementos nas variáveis de $1^{\mathrm{a}}$ ordem. A Tabela 1 mostra os primeiros resultados.

Tabela 1 - AVE e Confiabilidade composta do constructo modelo de gestão

\begin{tabular}{l|c|c}
\hline Variáveis & AVE & $\begin{array}{c}\text { Confiabilidade } \\
\text { composta }\end{array}$ \\
\hline Modelo de Gestão & 0,687 & 0,938 \\
Organização & 0,549 & 0,893 \\
Planejamento & 0,770 & 0,930 \\
Execução & 0,470 & 0,811 \\
Controle & 0,692 & 0,869 \\
\hline
\end{tabular}

As variáveis de primeira ordem sinalizaram variância média extraída superior a 0,5 e a confiabilidade composta acima de 0,7 , bem como alfa de Cronbach também superior a 0,7 .

O valor da confiabilidade de 0,938 revelou consistência interna adequada entre as variáveis de $1^{\mathrm{a}}$ e de $2^{\mathrm{a}}$ ordens. A AVE mostrou que 0,687 foi a variância comum das variáveis que contribuíram para o constructo, à medida que, se analisado o alpha de Cronbach, se percebe que ele, da mesma maneira, apresentou consistência interna alta de 0,948.

Os resultados apontaram a variável de $1^{a}$ ordem planejamento como sendo a mais representativa dentro da variável de $2^{\mathrm{a}}$ ordem modelo de gestão nas empresas da amostra. A seguir, aparece o controle. Percebe-se que duas fases do processo administrativo (planejamento e controle) ganham destaque dentro do constructo.

Notou-se que o elemento execução apontou os valores mais baixos dentro do constructo, conforme já observado na seção anterior. 


\subsection{Controles gerenciais (CG)}

\subsubsection{Estatística descritiva dos controles gerenciais}

Resultados obtidos por meio da estatística descritiva no que concerne aos controles gerenciais.

a) Métodos e sistemas de custeio

$\mathrm{Na}$ Figura 3 apresentam-se os resultados da pesquisa relativos a utilização dos métodos e sistemas de custeio.

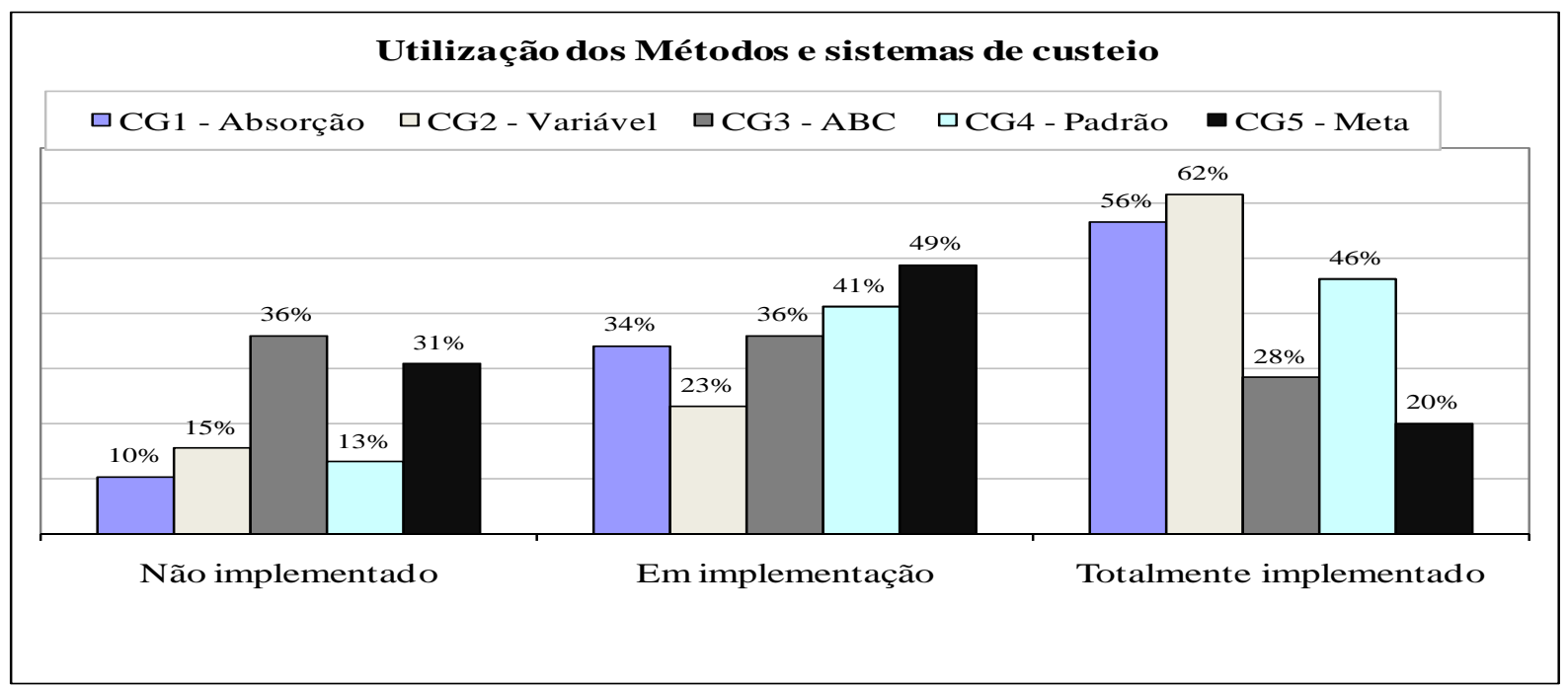

Figura 3 - Métodos e sistemas de custeio

Analisando-se os valores da Figura 3, percebe-se que das empresas pesquisadas mais da metade, $56 \%$, adotam o custeio por absorção para apropriar os custos. Isso pode ser entendido à medida que a atividade da indústria é mais complexa do que as empresas de outros setores. No caso dessas empresas, todos os custos de produção são distribuídos para os produtos, levando em conta os princípios contábeis.

Ao se tratar do método de custeio variável plenamente utilizado, tem-se $62 \%$, ou seja, mais da metade das empresas industriais separam os custos fixos e variáveis inerentes aos bens produzidos para fins de munir os gestores com informações para suas tomadas de decisões.

Das empresas pesquisadas, $36 \%$ não adotam o custeio $A B C$ em suas atividades. Há o registro do mesmo montante, $36 \%$, que estão implementando ou que possuem parcialmente o mencionado custeio, enquanto que em $28 \%$ o $A B C$ está sendo totalmente utilizado.

Sendo o custeio padrão um instrumento de controle dos custos de produção, o qual serve como referência para compararem-se os custos reais e os preestabelecidos, percebe-se que sua adoção plena concentra $46 \%$ das respostas à pesquisa. Além disso, em 49\%, praticamente metade das empresas, o custeio meta existe, porém sua utilização não ocorre plenamente e em todas as situações.

As relações mais expressivas dentro deste grupo apontaram para o método de custeio por absorção, custeio baseado em atividades e custeio meta, ao passo que o menor peso entre as associações se destinou ao método de custeio variável, oscilando, no total, entre 0,489 e 0,852 .

b) Indicadores de avaliação de desempenho

Na Figura 4 consta a utilização dos indicadores de avaliação de desempenho nas 
empresas pesquisadas.

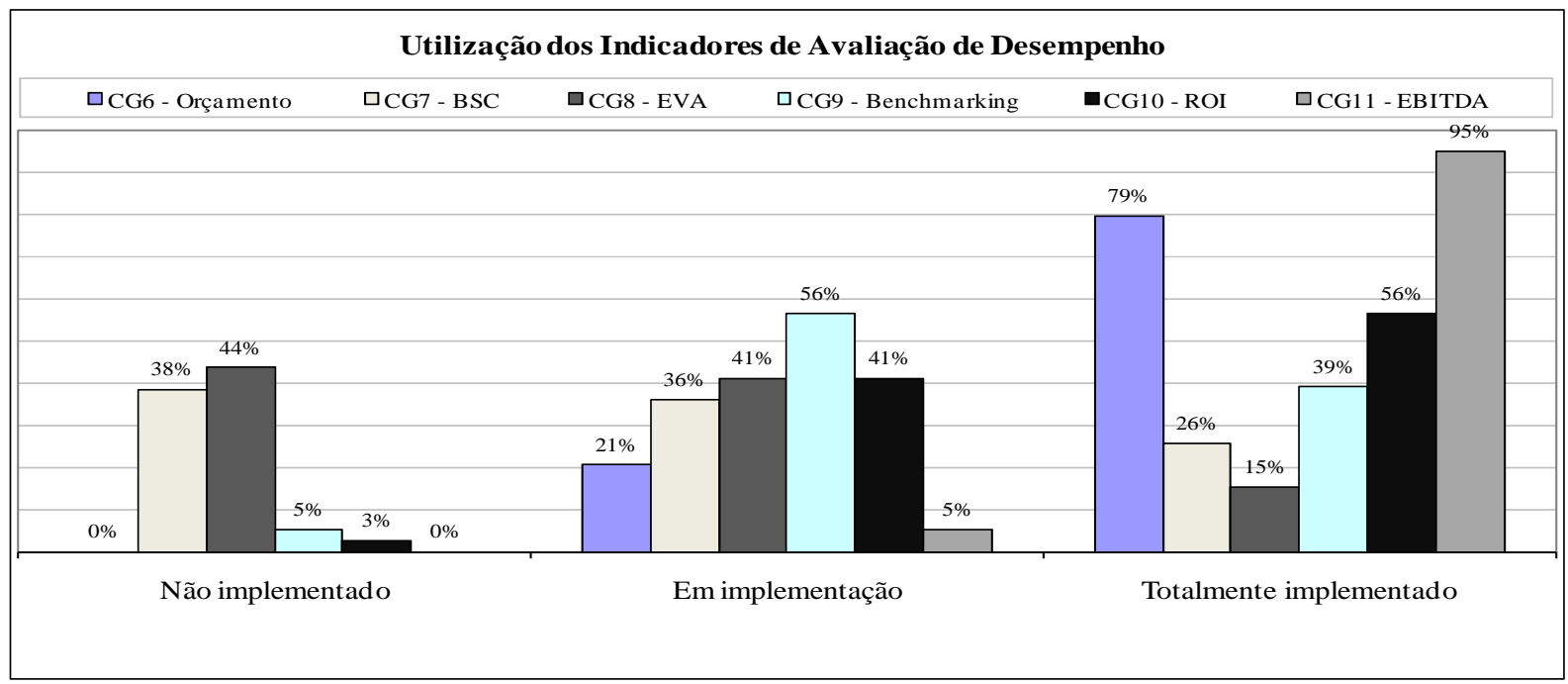

Figura 4 - Indicadores de avaliação

Um número relativamente baixo de empresas parece ter o orçamento sem utilizá-lo plenamente. Isso se reflete em $21 \%$ das indústrias. Entretanto, a maior concentração de respostas indica a utilização plena do orçamento em suas empresas. Em $79 \%$ das indústrias ocorre a utilização total do orçamento como instrumento de controle e avaliação de desempenho.

Note-se que, em parte considerável dessas empresas que adotam o orçamento como um instrumento usual, a sua elaboração ocorre, de forma participativa, em $23 \%$ das indústrias (variável MG9). A mesma tendência é observada na variável MG16, que verifica se os resultados previstos no orçamento são utilizados como parâmetro para a avaliação de desempenho.

Em uma proporção absolutamente menor do que a do orçamento, aparecem as empresas que adotam o Balanced Scorecard (BSC) como instrumento de controle gerencial. Somente para $26 \%$ das indústrias pesquisadas o $B S C$ parece ser considerado uma importante ferramenta de gestão a ponto de ser implementado e utilizado formalmente. Essa metodologia de suporte à tomada de decisão não é utilizada por $38 \%$ das indústrias.

A técnica de avaliação de desempenho EVA, de acordo com as respostas obtidas por este estudo, não é usada por $44 \%$ de empresas da indústria.

Por ser uma prática de contínua comparação dos produtos, serviços e modelos empresariais entre as empresas e os seus concorrentes ou líderes de mercado, possibilitando a criação de novos padrões ou melhoria de processos, é possível entender os motivos pelos quais praticamente metade das empresas da amostra adota o Benchmarking como prática usual. Apenas 5\% das empresas industriais não utilizam essa prática, tampouco aparece em processo de implementação.

Nota-se também que $56 \%$ das empresas utilizam o ROI em suas atividades rotineiras como um indicador de avaliação de desempenho. Quando analisado o EBITDA como um dos indicadores de avaliação de desempenho da empresa, percebe-se tendência alta de utilização entre as empresas. Tem-se $95 \%$ das respostas, sinalizando que essas empresas sempre utilizam o EBITDA quando estão controlando seus resultados, avaliando os desempenhos gerais das atividades ou em suas tomadas de decisões.

Dentro do seu grupo, a variável que assinalou maior significância em suas relações foi a CG9 (Benchmarking). Esse resultado estatístico pode se justificar à medida que as indústrias pesquisadas parecem estar implementando crescentemente o indicador Benchmarking em suas 
estruturas. Ao contrário, o nível menos expressivo de associação ficou a cargo do $B S C$, talvez por ser um sistema de indicadores não divulgado em meio a todas as empresas, ou, por guardar certo grau de complexidade em sua implementação.

c) Filosofias e conceitos aplicados para fins de controle gerencial

$\mathrm{Na}$ Figura 5 apresentam-se os resultados da pesquisa relativos a utilização das filosofias e conceitos aplicados para controle gerencial.

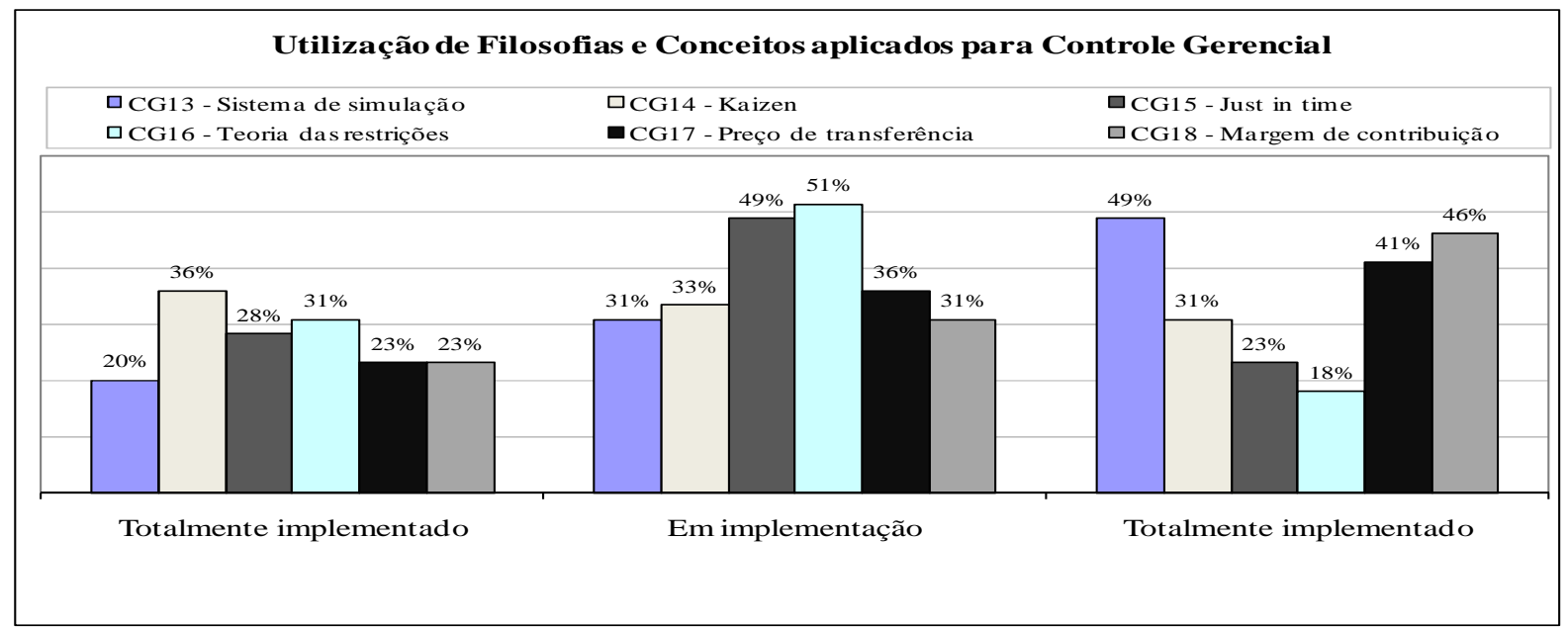

Figura 5 - Filosofias e conceitos

Sabendo-se que a simulação é uma técnica que permite avaliar os resultados que poderão ser encontrados em situações reais, propiciando aos gestores informações que lhes permitam tomar decisões mais adequadas; tem-se que ela é adotada plenamente por $49 \%$ das indústrias pesquisadas neste estudo, conforme pode ser visto na Figura 5. Não utilizam sistemas de simulação como indicador de avaliação de desempenho $20 \%$ das indústrias.

Das empresas, $31 \%$ têm o Kaizen totalmente implementado, sendo que $33 \%$ delas se mostram em processo de implementação e $36 \%$ não o possuem. Isso porque elas podem adotar outras filosofias, conceitos e técnicas em detrimento dessa aqui analisada ou pelo fato de ela não ser conhecida pelos seus gestores.

As empresas destacam-se mostrando que $23 \%$ delas têm o Just in Time como parte de suas atividades produtivas. Já $49 \%$ das indústrias mostram que estão implementando ou que não finalizaram a adoção dessa filosofia.

Assim como ocorreu com o Kaizen e com o Just in time, também os dados mostraram que em sua maioria as empresas não têm o conceito de teoria das restrições aplicado em seus processos ou, então, adotam em partes tal conceito na execução das atividades-fim de cada uma. Nessa linha, observa-se na Figura 5 que 31\% das empresas não adotam o conceito em suas atividades produtivas.

O conceito de preço de transferência registra quantidades maiores de empresas que o tem totalmente implementado em suas estruturas em comparação às filosofias anteriormente tratadas. Nessa linha, aparecem $41 \%$ das empresas. Em 36\% o conceito está sendo implementado ou é adotado parcialmente.

Esperava-se obter resultados que indicassem que a maior parte das empresas adota o conceito de margem de contribuição, haja vista ser ele direcionado para a análise da rentabilidade da empresa, dos produtos, dos serviços, sendo um dos instrumentos úteis para a tomada de decisões. No entanto, em $23 \%$ das indústrias, o conceito aqui tratado não é utilizado.

Por outro lado, percebe-se que há o esforço de parte das empresas em utilizar 
conceitos para fins de controle gerencial, o que fica transparente quando observado $31 \%$ das indústrias adotando parcialmente o conceito da margem de contribuição. Praticamente metade dessas empresas usa o mencionado conceito para tomar decisões e controlar os desempenhos.

As cargas dentro do modelo de equações se mostraram, em geral, expressivas quando se tratam das relações entre as variáveis e o grupo de controles. As únicas variáveis que revelaram valores mais baixos dizem respeito ao preço de transferência e à margem de contribuição.

\subsubsection{Avaliação do modelo de mensuração dos controles gerenciais}

Da mesma maneira que as variáveis do modelo de gestão foram analisadas, os controles gerenciais consistem na variável de $2^{\mathrm{a}}$ ordem e as demais variáveis são de $1^{\mathrm{a}}$ ordem. Observam-se os resultados do modelo no que tange à AVE e à confiabilidade composta conforme Tabela 2.

Tabela 2 - AVE e Confiabilidade composta do constructo controles gerenciais

\begin{tabular}{l|c|c}
\hline Variáveis & AVE & $\begin{array}{c}\text { Confiabilidade } \\
\text { composta }\end{array}$ \\
\hline Controles Gerenciais & 0,571 & 0,796 \\
Métodos e sistemas de custeio & 0,334 & 0,561 \\
Indicadores de aval. de desempenho & 0,327 & 0,767 \\
Filosofias e conceitos & 0,481 & 0,843 \\
\hline
\end{tabular}

Com 0,571 a variável de $2^{\mathrm{a}}$ ordem apresentou valor adequado de variância média extraída, significando que as variáveis de $1^{\text {a }}$ ordem são representativas dentro de seu constructo. A confiabilidade composta de 0,796 indica que há consistência interna entre as variáveis, o que é confirmado quando se analisa, também, o alfa de Cronbach de 0,761.

A única variável que registrou valor inferior a 0,7 foi métodos e sistemas de custeio, mas, de qualquer forma, o seu valor de 0,561 pode ser considerado aceitável para essa pesquisa. Já, quando se analisa a variância extraída média, percebe-se que as variáveis de $1^{\text {a }}$ ordem métodos e sistemas de custeio e indicadores de avaliação de desempenho são menos representativas dentro do constructo, sinalizando 0,334 e 0,327 respectivamente. A variável filosofias e conceitos revelou AVE de 0,481 $(0,5)$, sendo a única a chegar no patamar recomendado. De toda forma, os valores não se mostraram significativamente abaixo do pressuposto, optando-se pela permanência de todas as variáveis.

\subsection{Validade discriminante}

Contemplam-se aqui as correlações entre as variáveis e a raiz quadrada da AVE. O pressuposto a ser atendido sugere que as correlações devam ser menores do que a raiz quadrada da AVE, na qual os indicadores têm relação mais forte com sua variável latente do que com as outras variáveis. Assim, procedeu-se ao teste de validade para os constructos. A Tabela 7 revela as correlações que foram comparadas com os valores das raízes da AVE.

Tabela 3 - Correlações dos constructos

\begin{tabular}{l|c|c}
\hline Variáveis & Modelo de gestão & Controles gerenciais \\
\hline Modelo de gestão & $\mathbf{0 , 8 2 8 9}$ & \\
Controles gerenciais & 0,5157 & $\mathbf{0 , 7 5 5 7}$ \\
\hline
\end{tabular}

Nota: Os valores em negrito na diagonal consistem na raiz quadrada da AVE para facilitar a avaliação da validade discriminante.

As correlações informadas na Tabela 3 se mostram menores do que a raiz quadrada da AVE, que apresentou 0,828 para o modelo de gestão e 0,755 para controles gerenciais. Isso 
indica que as variáveis de $1^{\mathrm{a}}$ ordem têm relação mais forte com a sua variável de $2^{\mathrm{a}}$ ordem do que com as variáveis de outro constructo. Há, portanto, relação significativa entre as variáveis.

\subsection{Modelo estrutural}

Os coeficientes atenderam aos critérios preestabelecidos. A variância dos controles gerenciais é explicada cerca de $32 \%$ pelo modelo de gestão. Aplicando-se o bootstrapping, as relações entre os constructos modelo de gestão e controles gerenciais resultaram em 2,198.

A associação entre modelo de gestão e controles gerenciais se mostrou significante $(4,433)$, indicando que os elementos do modelo de gestão se associam significativamente com os controles gerenciais adotados pelas empresas pesquisadas.

\subsection{Análise geral das associações}

De forma geral, as seções anteriores mostraram nível de associação entre as variáveis de cada constructo e o seu próprio constructo e entre os dois constructos pesquisados. Os resultados dos modelos evidenciaram que todos os elementos pesquisados contribuem significativamente para a formação do modelo de gestão, bem como todos os controles investigados denotaram expressividade dentro do grupo geral. Diante disso, a associação entre modelo de gestão e controles gerenciais também se mostrou saliente, após analisados os pressupostos da técnica de modelagem de equações estruturais.

Os modelos de equações e a análise descritiva das respostas atribuídas ao instrumento de pesquisa permitiram inferências adicionais acerca das associações entre os elementos e os controles. Verificou-se que as empresas munidas de estrutura organizacional mais bem delineada, com funções claramente definidas, delegação de autoridade aos gestores, atividades claras e delimitadas, responsabilidade compatível com funções, mais poder formal, bem como divulgação e formalização do organograma, mostram maior interesse na adoção de controles gerenciais novos e adequado sucesso em suas implementações, assim como demonstram conhecimento sobre controles menos conhecidos, tais como Kaizen, preço de transferência e teoria das restrições. Em linhas gerais, as variáveis do elemento organização (delegação de autoridade e compatibilidade entre autoridade, responsabilidades e funções atribuídas) se associaram, em maior nível, com a adoção do custeio $A B C$, custeio meta, Benchmarking e a filosofia Just in Time.

Outra evidência revelou que as empresas nas quais os gestores são envolvidos no processo de planejamento, que divulgam as estratégias e têm estilo participativo, tendem a conhecer os controles disponíveis para adoção em suas estruturas e implementá-los gradativamente, principalmente, aqueles do grupo de filosofias e conceitos para fins de controle gerencial. Nesse ínterim, destacam-se o Just in Time e o conceito de teoria das restrições.

As empresas que apontaram para a existência de autonomia do gestor em tomar as decisões necessárias durante a execução do orçamento e para o fato de todas as ações serem pautadas no orçamento previamente estabelecido, também mostraram considerável interesse em implementarem controles gerenciais, especialmente aqueles voltados para a área operacional (de produção) - grupo filosofia e conceitos aplicados para fins de controle gerencial.

Nas empresas onde os gestores são comprometidos com o monitoramento e controle dos resultados em relação aos planos traçados e onde há um controle dos desvios entre o que foi executado versus planejado, o grupo de controles relativo aos indicadores ganha ênfase, na mesma proporção que as filosofias e conceitos. Nesse quesito, o controle mais utilizado no processo de controle e monitoramento é o orçamento, seguido pelo Benchmarking, BSC, ROI 
e EBITDA. Os controles EVA e índice de crescimento de receita líquida se apresentaram com graus de associação inferiores.

Observando-se as respostas obtidas, percebe-se que, em última instância, as empresas se classificam dentro de uma escala mediada, onde nem sempre os elementos do modelo de gestão se aproximam do ideal; algumas empresas se encontram em processo de implementação de mudanças e muitas não possuem planejamento, execução e controle como processo formal em suas estruturas. Assim também, há a observância de que a maior parte das empresas pesquisadas não têm os controles gerenciais totalmente implementados. Todavia, notou-se que quanto mais formal, participativa e monitorada a empresa for, maior a tendência à implementação dos controles gerenciais ela apresenta.

\section{CONSIDERAÇÕES FINAIS}

O objetivo do estudo foi o de investigar as associações entre os elementos do modelo de gestão e os controles gerenciais das empresas. Em se tratando do constructo modelo de gestão, alguns elementos se mostraram mais importantes do que outros. Os elementos por ordem de representatividade foram: planejamento, controle, organização e execução. As empresas mostraram enfatizar, dentro do modelo de gestão, os elementos planejamento e controle, o que parece plausível haja vista que suas atividades envolvem maior complexidade e, por isso, necessitam ser adequadamente planejadas e seus resultados controlados.

Constatou-se, aceitando a hipótese desenhada, que os elementos do modelo de gestão influenciam, significativamente, os tipos de controles gerenciais adotados pelas empresas. Os métodos e sistemas de custeio mais utilizados pelas indústrias consistiram em: absorção, $A B C$, padrão e meta; os indicadores de avaliação de desempenho foram: orçamento, Benchmarking, ROI, EBITDA; e as filosofias e conceitos foram: sistemas de simulação, Kaizen, Just in Time, teoria das restrições, preço de transferência e margem de contribuição.

Notou-se que as empresas investigadas utilizam com menos frequiência os controles EVA e BSC. Em contrapartida, os métodos e sistemas e os demais controles aparecem predominantemente como apoiadores na execução de suas atividades.

Em se tratando da ordem por representatividade dentro do constructo controles gerenciais, apareceu em primeiro lugar os indicadores de avaliação de desempenho, seguido das filosofias e conceitos e por último os métodos e sistemas de custeio.

Concluiu-se que as variáveis investigadas apresentaram níveis significativos de associação nos seus constructos e que o constructo modelo de gestão mostrou relevante associação com o constructo controles gerenciais, indicando, portanto, que os elementos organização, planejamento, execução e controle do modelo de gestão têm, em linhas gerais, significativa associação com os tipos de controles gerenciais adotados pelas indústrias investigadas.

\section{REFERÊNCIAS}

ANDERSON, H. R.; NEEDLES, B. E. Jr.; CALDWELL, J. C. Managerial Accounting. Boston: Houghton Mifflin, 1989.

ANTHONY, R. N.; GOVINDARAJAN, V. Sistemas de controle gerencial. São Paulo: Atlas, 2002.

ATKINSON, A.; BANKER, R. D.; KAPLAN, R. S.; YOUNG, M. Contabilidade gerencial. São Paulo: Atlas, 2000.

BERTALANFFY, L. V. Teoria geral dos sistemas. Petrópolis: Vozes, 1977.

CATELLI, A. (Org.). Controladoria: uma abordagem da gestão econômica GECON. São 
Paulo: Atlas, 2001.

CHENHALL, R. H. Management control systems design within its organizational context: findings from contingency-based research and directions for the future. Accounting, Organization and Society, v. 28, p.127-168, 2003. doi:10.1016/S0361-3682(01)00027-7

CHIN, W. W. The partial least squares approach to structural equation modeling. In: MARCOULIDES, G. A. Modern Methods for Business Research. Mahwah, NJ: Lawrence Erlbaum Associates, 1998. pp. 295-358.

COAD, A. F. Some survey evidence on the learning and performance orientations of management accountants. Management Accounting Research, n 10, p. 109-135, 1999. doi:10.1006/mare.1998.0083

COOPER, D. R.; SCHINDLER, Pamela S. Métodos de pesquisa em administração. Porto Alegre: Bookman, 2004.

COZBY, P. C. Métodos de pesquisa em ciências do comportamento. Trad. Paula Inez Cunha Gomide, Emma Otta e José Oliveira Siqueira. São Paulo: Atlas, 2003.

DAFT, R. I. Administração. São Paulo: Pioneira Thomson Learning, 2004.

DEAL, T.; KENNEDY, A. Corporate culture: The rites and rituals of the corporate life. Massachusetts: Addison-Wesley, 1982.

FAYOL, H. Administração industrial e geral: previsão, organização, comando, coordenação, controle. São Paulo: Atlas, 1989.

GORDON, G. G.; DITOMASO, N. Predicting corporate performance from organizational culture. Journal of management studies, v. 29, n. 6, Nov., 1992. doi:10.1111/j.14676486.1992.tb00689.x

GUERREIRO, R. Modelo Conceitual de Sistemas de Informação de Gestão Econômica: uma contribuição à teoria da comunicação da contabilidade. 1989. Tese (Doutorado em Ciências Contábeis) - Faculdade de Economia, Administração e Ciências Contábeis da Universidade de São Paulo, São Paulo, 1989.

GERREIRO, R. A teoria das restrições e o sistema de gestão econômica: uma proposta de integração conceitual. 1995. Tese (Livre Docência) - Departamento de Contabilidade da Faculdade de Economia, Administração e Ciências Contábeis da Universidade de São Paulo, São Paulo, 1995.

HAIR, J. F.; ANDERSON, R. E.; TATHAN, R. L.; BLACK, W. C. Análise multivariada de dados. Porto Alegre: Bookman, 2007.

HANSEN, J. E. Aplicação do custeio alvo em cursos de pós-graduação lato sensu: um estudo sob o enfoque da gestão estratégica de custos. 2002. Dissertação (Mestrado em Ciências Contábeis) - Faculdade de Economia, Administração e Contabilidade da Universidade de São Paulo.

HENSELER, Jorg; RINGLE, Christian M.; SINKOVICS, Rudolf R. The use of partial least squares path modeling in international marketing. New Challenges to International Marketing, advances in international marketing, v. 20, p. 277-319, 2009. doi:10.1108/S1474-7979(2009)0000020014

HORnGREN, C. T.; FOSTER, G.; DATAR, S. M.. Contabilidade de custos. 9. ed. Rio de Janeiro: LTC, 2000.

HUGHES, S. B.; GJERDE, K. A. P. Do different cost systems make a difference? 
Management Accounting Quarterly, Montivale, v. 1, n. 5, p. 22-30, 2003.

KAPLAN, R. S.; COOPER, R. Custo \& desempenho: administre seus custos para ser competitivo. São Paulo: Futura, 1998.

KAPLAN, R. S.; NORTON, D. P. A estratégia em ação: Balanced Scorecard. Rio de Janeiro: Campus, 1997.

KOTTER, J. P.; HESKETT, J. L. A cultura corporativa e o desempenho empresarial. São Paulo: Makron, 1992.

LIKERT, R. A organização humana. São Paulo: Atlas, 1975.

LOUDERBACK III, J. G.; HOLMEN, J. S.; DOMINIAK, G. F. Managerial Accounting. Ohio: South-Western College Publishing, 2000.

MARCOULIDES, G.; HECK, R. Organizational culture and performance: proposing and testing a model. Organization Science, v. 4, n. 2, p. 209-225, May, 1993. doi:10.1287/orsc.4.2.209

MARTINS, E. Contabilidade de custos. São Paulo: Atlas, 2003.

MAXIMIANO, A. C. A. Introdução à administração. São Paulo: Atlas, 1995.

MENDES-DA-SILVA, W.; BIDO, D. S.; FORTE, D. Identificando atributos que influenciam o desempenho do professor de finanças: evidências empíricas por meio de equações estruturais. In: ECONTRO ANUAL DA ASSOCIAÇÃO NACIONAL DOS PROGRAMAS DE PÓS-GRADUAÇÃO EM ADMINISTRAÇÃO, 32., 2008, Rio de Janeiro. Anais... Rio de Janeiro: ANPAD, 2008.

MONDEN, Y. Cost reduction systems: target costing and Kaizen costing. USA: Portland, 1993.

MOORE, J. H.; WEATHERFORD, L. R. Tomada de decisão em administração com planilhas eletrônicas. Porto Alegre: Bookman, 2005.

NASCIMENTO, A. M.; REGINATO, L. Controladoria: instrumento de apoio ao processo decisório. São Paulo: Atlas, 2010.

OTLEY, D. T. The contingency theory of management accounting: achievement and prognosis. Accounting, Organizations and Society, v. 5, n. 4, p. 413-428, 1980. doi:10.1016/0361-3682(80)90040-9

PADOVEZE, C. L. Contabilidade gerencial: um enfoque em sistema de informações contábil. São Paulo: Atlas, 2004.

PIDD, M. Modelagem empresarial: uma ferramenta para a tomada de decisão. Porto Alegre: Bookman, 1998.

REGINATO, L. Um estudo setorial sobre as relações entre variáveis ambientais externas, modelos de gestão, controles gerenciais e desempenhos das empresas. 2010. Tese (Doutorado em Ciências Contábeis) - Faculdade de Economia, Administração e Contabilidade, Universidade de São Paulo, 2010.

ROBBINS, S. P. O processo administrativo: integrando teoria e prática. São Paulo: Atlas, 1978.

SAKURAI, M. Gerenciamento integrado de custos. São Paulo: Atlas, 1997.

SANTOS, R. V.; NININ, A. C. S. Realidade dos sistemas de custos em empresas de grande porte. In: CONGRESSO INTERNACIONAL DE CUSTOS, 6., 1999, Braga. Anais... 
Portugal: 1999.

SOUTES, D. O.; GUERREIRO, R. Uma Investigação do Uso de Artefatos da Contabilidade Gerencial por Empresas Brasileiras. In: ECONTRO ANUAL DA ASSOCIAÇÃO NACIONAL DOS PROGRAMAS DE PÓS-GRADUAÇÃO EM ADMINISTRAÇÃO, 31., 2007, Rio de Janeiro. Anais... Rio de Janeiro: ANPAD, 2007.

STEINER, G. A.; MINER, J. B. Política e estratégia administrativa. Rio de Janeiro: Interciência, 1981.

STEWART III, B. G. The quest for value: the EVA management guide. New York: Harper Business, 1990.

STONER, J.; FREEMAN, R. E. Administração. Rio de Janeiro: Prentice-Hall, 1985.

TAYLOR, F. W. Princípios de administração científica. São Paulo: Atlas, 1995.

SULAIMAN, M.; AHMAD, N.; ALWIN, N. Management accounting practices in selected Asian countries. Managerial Auditing Journal, v. 19, n. 4, p. 493-508, 2004. doi:10.1108/02686900410530501

TEN HAVE, S. Modelos de gestão: o que são e quando devem ser usados. São Paulo: Pearson Prentice Hall, 2003.

TURBAN, E.; MCLEAN, E.; WETHERBE, J. Tecnologia da informação para gestão: transformando os negócios na economia digital. Porto Alegre: Bookman, 2004.

VOSS, Christopher A.; PÄR ÄHLSTRÖM; BLACKMON, K. Benchmarking and operational performance: some empirical results. International Journal of Operations \& Production Management, v. 17, 10, p. 1046-1058, 1997. doi:10.1108/01443579710177059 